\title{
A NATUREZA MATEMÁTICA: DA ALMA DA TERRA COMO POTÊNCIA GEOMETRIZANTE NO OPÚSCULO DA NEVE HEXAGONAL DE JOHANNES KEPLER
}

Anastasia Guidi ITOKAZU ${ }^{1}$

- RESUMO: Na física celeste apresentada em sua Astronomia nova, Kepler explica os movimentos planetários através da ação de uma certa força ou potência motriz solar. Em vista da aproximação feita no livro entre física celeste e explicações baseadas em "causas corpóreas", chamam a atenção as numerosas passagens onde Kepler refere-se às noções de alma e mente planetária. No presente artigo discutimos esses trechos pouco comentados da Astronomia nova. Com o objetivo de iluminar a discussão, abordamos na segunda seção a definição de alma terrestre delineada por Kepler no opúsculo Da neve hexagonal, escrito logo após a publicação da Astronomia nova. Kepler atribui a forma hexagonal dos flocos de neve a uma certa faculdade formadora da alma da Terra, que agiria como uma potência geometrizante com a finalidade de otimizar a saída do calor no processo de congelamento.

- PALAVRAS-CHAVE: Kepler, astronomia física, flocos de neve, alma, mente.

No início do século XVII, o astrônomo alemão Johannes Kepler contribuiu para a dissolução da dicotomia entre céu e terra ao construir uma astronomia de precisão baseada em causas físicas, na qual os movimentos dos planetas são explicados segundo o exemplo dos fenômenos magnéticos observados na região terrestre. O movimento da Lua é explicado por Kepler, na Astronomia nova (1609), como um efeito do magnetismo da Terra, que havia sido recentemente descoberto por William Gilbert (Kepler, 1992b, p.400-3; Kepler, 1938-, v.3, p.252-4). Analogamente, os movimentos planetários no sistema heliocêntrico são atribuídos à ação da força ou potência motriz solar (Kepler, 1992b, p.376-384; Kepler, 1938-, v.3, p.236-42).

1 É Doutora em Filosofia pela Universidade Estadual de Campinas (Unicamp) e bolsista da Fapesp de pós-Doutorado na Unicamp. Artigo recebido em 02/08 e aprovado em 06/08. 
A Astronomia nova consiste em uma narrativa histórica daquela que Kepler denominou sua "guerra contra Marte", o longo trabalho de análise das observações relativas ao planeta previamente coletadas por Tycho Brahe e sua equipe no observatório de Uraniburgo. O estudo do movimento de Marte conduziu Kepler à descoberta da forma elíptica das órbitas dos planetas, bem como da "lei das áreas", que descreve a velocidade variável do planeta em seu percurso. ${ }^{2}$ O argumento do livro indica o caminho através do qual é possível vir a conhecer os verdadeiros movimentos celestes a partir das observações, visto que estas últimas podem ser reproduzidas por diferentes modelos geométricos e, segundo diferentes sistemas de mundo. Seu título completo diz Astronomia Nova "explicando as causas" ou física celeste apresentada através de comentários sobre os movimentos da estrela Marte segundo as observações do homem de ilustre família Tycho Brahe. O conceito matematizado de força solar desempenha um papel central na determinação da órbita elíptica de Marte, pois funciona como critério de seleção entre os diversos modelos geométricos possíveis do ponto de vista do acordo com as observações. Em carta a Herwart von Hohenburg, Kepler escreve a respeito da Astronomia nova:

Muito tenho indagado a respeito de causas físicas. O meu objetivo aqui é dizer que a máquina celeste não é como um ser animado ou divino, mas como um relógio (esse relógio que acredita-se ser animado, e que concede à obra a glória do criador); e que nela quase toda a variedade dos movimentos se deve a uma simplíssima força corpórea, como no relógio todos os movimentos se devem a um simplíssimo peso. (Kepler, 1938-, v.15, p.146)

É, portanto, algo surpreendente que Kepler recorra freqüentemente na Astronomia nova às noções tradicionais de alma e mente planetária. Se o objetivo do livro é o estabelecimento de uma nova astronomia física, fundada em causas corpóreas, por que deveria o autor sequer mencionar as almas e mentes de uma cosmologia que distinguia essencialmente os seres terrestres dos seres celestes e era ontologicamente incompatível com o copernicanismo? E como explicar que, em 1610, após a publicação da Astronomia nova, Kepler retome, no opúsculo Da neve hexagonal, a noção de alma da Terra ao tecer uma explicação para a forma regular dos flocos de neve?

No presente artigo discutimos os dois contextos onde o recurso às mentes e almas planetárias é mais notável na Astronomia nova: a avaliação, a partir de considerações físicas, dos modelos geométricos desenvolvidos

2 A segunda lei de Kepler procura estabelecer uma relação entre a velocidade de um planeta em uma dada região de seu percurso e sua distância ao Sol naquela região. Em sua formulação final, a lei das áreas mantém que a linha que liga o planeta ao Sol varre áreas iguais em tempos iguais. 
na Antigüidade para reproduzir o movimento de Marte, na primeira parte do livro e, a tentativa de construção de explicações físicas para a excentricidade da órbita circular do planeta, no capítulo 39, e para a sua forma elíptica, no capítulo 57. Na primeira seção, abordamos a distinção entre alma e mente planetária, procurando esclarecer o escopo da introdução desses conceitos nas análises físicas desenvolvidas por Kepler. Em seguida, passamos a um exame da concepção de alma da Terra como faculdade geometrizante assim como ela aparece no opúsculo Da neve hexagonal. Transportada para a Astronomia nova, essa concepção de alma planetária parece-nos suficientemente próxima da noção kepleriana de força corpórea para que afirmemos ser apenas aparente a contradição apontada acima.

\section{Forças corpóreas, almas e mentes na Astronomia nova}

Em seu primeiro trabalho astronômico publicado, o Mistério cosmográfico, de 1596, Kepler explicara os movimentos dos planetas através da ação de uma alma motriz situada no Sol. ${ }^{3}$ Em Mistério, a possibilidade de substituir as almas individuais dos planetas por uma única alma motriz, situada no centro do sistema, fora apresentada como uma vantagem notável do heliocentrismo. Na Astronomia nova a alma motriz do Sol é substituída pelo conceito matematizado de força (vis) ou potência (virtus) solar. A natureza dessa força é em grande medida definida através da analogia com a luz. Luz e força motriz são species imateriais (Kepler, 1992b, p.382), aptas a transportar a influência de um corpo até outro corpo espacialmente distante. Kepler observa que a força solar não pode no entanto ser identificada com a luz, ou os planetas mover-se-iam mais lentamente quando parte dessa luz fosse obstruída por outro corpo celeste, como por ocasião dos eclipses, o que não é observado. Ele considera plausível que a força solar seja magnética ou quase-magnética, visto que ela age à distância e que fora recentemente demonstrada por William Gilbert no seu De Magnete a natureza magnética da Terra.

Kepler estabelece a distinção entre almas e mentes planetárias ao descrever o sistema aristotélico das esferas homocêntricas: "Assim, ele [Aris-

3 "Pois assim como a fonte da luz está no Sol, e a origem do círculo está no lugar do Sol, isto é, no centro, assim aqui a vida, o movimento e a alma do mundo são recolhidos nesse mesmo Sol, de modo que caiba às [estrelas] fixas o repouso, aos planetas os atos segundos dos movimentos e ao Sol o próprio ato primeiro, que é incomparavelmente mais nobre do que os atos segundos em todas as coisas. E não é de maneira distinta que o mesmo Sol sobressai amplamente em relação a todos os demais [astros] pela beleza de seu aspecto, pela eficácia de sua força e pelo esplendor de sua luz" (Kepler, 1992a, p.193-4; Kepler, 1938-, v.1, p.70). 
tóteles] introduziu para nós mentes separadas, numa palavra, deuses, como os perpétuos administradores dos movimentos celestes. Eles também introduziram uma alma motriz, mais intimamente ligadas aos orbes e conferindo-lhes forma, para que só restasse à mente dar assistência" (Kepler, 1992b, p.125; Kepler, 1938-, v.3, p.67).

De acordo com a descrição fornecida por Kepler, é possível distinguir na astronomia aristotélica as almas dos planetas, faculdades motoras [facultas movens] que funcionam imprimindo aos orbes suas velocidades, e às mentes dos planetas, estas últimas próximas da vontade humana na medida em que dirigem os movimentos impressos nos corpos pelas almas. Os orbes sólidos determinam a região do espaço onde cada planeta deve mover-se, como a bengala de um cego aponta-lhe o caminho (Kepler, 1992b, p.126; Kepler, 1938-, v.3, p.69). A força motriz que imprime a velocidade de cada orbe é associada à alma do planeta, enquanto a mente indica a direção em que deve dar-se o movimento. Kepler observa que as mentes planetárias eram necessárias no universo eterno de Aristóteles, mas não o são em um mundo criado por Deus e provido de esferas cristalinas. Deus, com efeito, poderia ter lançado os orbes em suas respectivas direções no instante da Criação e, neste caso, as mentes planetárias tornar-se-iam supérfluas. Já as almas planetárias são necessárias no esquema aristotélico mesmo que se admita a criação do mundo, pois as velocidades dos orbes devem ser atribuídas às causas que operam continuamente, enquanto durarem os movimentos.

No segundo capítulo da Astronomia nova, Kepler trata da equivalência entre o círculo excêntrico e o sistema de epiciclo e deferente, os dois modelos geométricos usualmente empregados, à sua época, na representação da primeira variação dos movimentos celestes. ${ }^{4}$ Os dois modelos também são tradicionalmente usados na representação da variação de velocidade observada no movimento do Sol, e a descoberta de sua equivalência remonta ao matemático grego Apolônio de Perga (c.262 - c.190 a.C.). O tema é abordado por Ptolomeu no livro III do Almagesto e por Copérnico no livro III do Das revoluções das esferas celestes. Na Astronomia nova, Kepler, após expor a equivalência geométrica, considera os dois esquemas do ponto de vista da sua física celeste. Nessa análise, são pressupostas a forma circular dos movimentos dos astros, idéia amplamente aceita desde a Antigüidade e que somente seria rompida com a própria Astronomia nova, e a inexistência dos orbes sólidos,

4 A primeira variação no movimento de um planeta corresponde no sistema copernicano ao movimento de translação do próprio planeta ao redor do Sol com velocidade variável, ao passo que a segunda variação corresponde ao movimento translacional da Terra. Este último é observacionalmente refletido no movimento de cada planeta como uma variação dependente da posição relativa do Sol. 
recentemente demonstrada por Tycho Brahe. ${ }^{5}$ Se o planeta deve descrever o seu percurso circular em um mundo desprovido de esferas cristalinas, livre no éter "como os pássaros no ar", sem o auxílio de estruturas que possam determinar as suas distâncias constantes relativamente ao centro de cada percurso, resta explicar como é possível a manutenção da forma circular dos movimentos.

Pois um círculo tanto é definido quanto completado pelo mesmo [critério], a saber, a igualdade das distâncias a partir do centro. E não importa quantas destas faculdades motrizes sejam alçadas, um círculo certamente não é, nem mesmo para Deus, nada além do que acaba de ser dito. É claro que os geômetras ensinam como, dados três pontos sobre a circunferência, continuar [a traçar] um círculo. Mas isso pressupõe que alguma porção da circunferência (aquela que passa pelos três pontos) já esteja acabada. (Kepler, 1992b, p.127-8; Kepler, 1938, v.3, p.69-70)

De acordo com essa passagem, um círculo não pode ser definido senão com relação ao seu centro, pois na outra construção possível já se dispõe de um conhecimento prévio do círculo, ou ao menos de uma parte dele. Ao dizer que o círculo é definido e completado (et definitur et perficitur) a partir da igualdade das distâncias que separam cada ponto da periferia até centro, Kepler aproxima-se dos geômetras gregos, em especial de Euclides. As definições da geometria euclidiana são provisórias até que seja provada a existência dos objetos referidos, e esta prova se dá com a construção desses objetos (Heath, 1981, p.374). No primeiro livro dos Elementos, quando é postulada a possibilidade de construção de um círculo, os parâmetros que entram em jogo são exatamente o centro e a "distância" ou raio (Euclides, 1956, v.1, p.154). A definição de círculo que Kepler considera apropriada é aquela que descreve a sua construção, a partir do centro e do raio constante. Ao associar essa definição de círculo aos movimentos circulares dos astros, Kepler deriva uma série de argumentos relativos à possibilidade de existência física dos modelos da astronomia tradicional em um mundo onde não há orbes sólidos.

Um círculo é definido como a figura geométrica na qual todos os pontos são eqüidistantes do centro e nenhuma causa, seja ela animal ou natural, pode operar independentemente dessa definição fundamental. Dessa maneira são banidos da astronomia todos os movimentos em torno de pontos vazios, em especial os movimentos sobre epiciclos.

5 Kepler refere-se aqui às medidas de paralaxe que demonstraram que os cometas são corpos que se movem na região celeste em órbitas muito alongadas, que atravessariam os orbes e os quebrariam caso estes fossem sólidos (Kepler, 1992b, p.122-9; Kepler, 1938-, v.3, p.66-71). Jardine (1988, p.230, n.14) aponta para o fato de que as esferas cristalinas haviam sido criticadas com base na experiência astronômica mesmo antes de Tycho Brahe. 
O que, então, mostrará ao planeta este lugar inicial, a partir de onde ele irá dispor o restante de seu percurso? Isso é impossível a menos que o motor do planeta (como na opinião de Avicena) imagine para si mesmo o centro de sua esfera e a sua distância até ele, ou seja auxiliado por alguma outra propriedade distinta do círculo na formação desse mesmo círculo. (Kepler, 1992b, p.128; Kepler, 1938-, v.3, p.70)

Quando Kepler emprega as noções de mentes e almas planetárias na análise dos modelos geométricos da astronomia tradicional, essas noções têm significados bem distintos. O recurso às mentes planetárias é retórico, como já foi apontado por Bruce Stephenson (1987, p.3). Empregadas hipoteticamente, as mentes planetárias têm a função de permitir a análise de problemas astronômicos em termos físicos gerais, operando como casos extremos que permitem a determinação da plausibilidade física dos diversos modelos possíveis do ponto de vista do acordo com as observações. As mentes planetárias são hipóteses provisórias, e têm a função de estabelecer a impossibilidade de determinadas configurações geométricas, mesmo que fosse concedida inteligência aos planetas. Isso é corroborado no capítulo 39:

Do mesmo modo, claramente, a mente do planeta não pode por si mesma medir sua posição ou distância ao Sol, já que entre ambos há o puro ar etéreo, desprovido de qualquer indicação. (Kepler, 1992b, p.413; Kepler, 1938-, v.3, p.260)

Aqui, o recurso às mentes dá-se no contexto da construção de uma teoria para explicar a aproximação e afastamento do planeta com relação ao Sol, de maneira a produzir uma órbita circular e excêntrica. A força solar age de maneira diferente sobre o planeta, conforme a sua distância, a origem dessa força varia, impelindo-o com maior ou menor velocidade. Essa força não pode no entanto explicar ela mesma porque a distância varia. A ação da força solar é simples, e produz movimentos circulares concêntricos com o Sol (Itokazu, 2006-b). A excentricidade dos percursos do Sol e dos planetas, conhecida desde a Antigüidade deve receber alguma explicação adicional. Kepler aventa duas alternativas: a alma do planeta ou o seu magnetismo, que o impeliria a se aproximar ou se afastar do Sol conforme cada um dos pólos estivesse dirigido ao centro do mundo. Essas duas possibilidades são operacionalmente equivalentes, isto é, elas conduzem ao mesmo tipo de modelo geométrico, e o autor não se esforça em distingui-las.

O argumento do capítulo 39 da Astronomia nova, consiste em uma demonstração de que a excentricidade de uma órbita circular não pode ser explicada de maneira consistente, mesmo que se conceda a existência de mentes planetárias, isto é, quaisquer que sejam as faculdades atribuídas ao planeta. Este capítulo antecede a introdução da elipse, na quarta parte do livro e, tem o objetivo de demonstrar que a órbita circular e excêntrica da tradição é irrealizável em um mundo onde já não existem orbes cristalinos. 
O pressuposto básico da demonstração é a impossibilidade de se usar pontos vazios de corpo como referência nas demonstrações astronômicas se o espaço é indiferenciado. Essa condição é mais geral e contém aquela que afirmara não poder um círculo ser construído em torno de um ponto vazio. O argumento de Kepler é longo e não convém reproduzi-lo aqui: tratase de demonstrar que a excentricidade da órbita circular de um planeta no sistema heliocêntrico, é definida como a distância do Sol ao centro da órbita, um ponto vazio, e que não há nenhuma relação geométrica capaz de expressar as distâncias consecutivas do planeta ao Sol que não leve em conta esse centro desprovido de corpo. Seria necessário que a mente do planeta fosse dotada de faculdades incríveis (incredibilia) para que ela pudesse descrever uma simples órbita circular e excêntrica. Vale notar que é justamente este argumento, indiferentemente válido, quer considere-se as explicações da cosmologia tradicional ou aquelas da nova física celeste, que precede $\mathrm{o}$ abandono da circularidade dos movimentos celestes e a introdução das órbitas elípticas.

No capítulo 57, Kepler procede uma investigação similar sobre a causa da variação na distância de Marte até o Sol, já tendo sido revelada a forma elíptica da órbita do planeta. Aqui a situação é menos complicada, pois ao contrário do que acontece no caso de um círculo excêntrico, existe um procedimento geométrico para a construção de uma elipse, ou em outras palavras, uma relação geométrica para expressar as distâncias dos focos até cada ponto sobre o limite da figura. O problema surge, no entanto, quando Kepler procura explicar fisicamente a aproximação e o afastamento do planeta com relação ao Sol, de maneira a formar a elipse através do magnetismo do planeta. Ocorre que, para que o planeta exibisse o padrão de movimento observado, seus pólos magnéticos deveriam situar-se em uma posição que não coincida com o eixo de rotação da Terra (Kepler, 1992b, p.559; Kepler, 1938-, v.3, p.355). Por esse motivo, Kepler retoma a investigação em termos mais gerais, e volta a considerar a possibilidade de que o planeta seja assistido por uma mente. Após uma análise elaborada, a conclusão é que mesmo uma mente teria de enfrentar problemas da mesma ordem:

Embora tenhamos permanecido incertos quanto à força magnética inerente a esses mesmos corpos dos planetas, pela consideração do eixo de Terra, que é diferente da linha que vai do Sol até a linha das apsides, esta dificuldade é comum às duas explicações. Pois ainda que tivéssemos suposto uma mente, seríamos impelidos a admitir o tipo de eixo que gostaríamos que houvesse na Terra, através de cuja mediação a mente pudesse apreender a força do ângulo, ou o seu "seno invertido". (Kepler, 1992b, p.559; Kepler, 1938-, v.3, p.355) 
As passagens aqui reproduzidas estabelecem com suficiente certeza que o emprego de mentes planetárias na Astronomia nova é retórico. Kepler não acredita seriamente na sua existência, e pode-se observar que o argumento do livro é tecido de maneira a minar a necessidade de associação de faculdades cognitivas aos planetas, demonstrando a sua inutilidade quando é conhecida a verdadeira estrutura geométrica dos movimentos. Já as almas dos planetas, estas são equivalentes, na Astronomia nova, às suas faculdades motoras intrínsecas, que podem ser interpretadas como magnéticas ou animadas (Kepler, 1992b, p.413, 560-8; Kepler, 1938-, v.3, p.259, 356, 361). É certo que Kepler opta pela explicação natural, como fica claro principalmente no prefácio à Astronomia nova. Ao longo do argumento do livro, porém, as almas planetárias funcionam como expressões mais gerais da força intrínseca ao planeta Marte, e são auxiliares na determinação dos parâmetros que determinam precisamente a sua natureza e o seu modo de operação.

Assim, o uso que o astrônomo faz das noções de alma e mente planetária na Astronomia nova é bastante distinto: enquanto as mentes são empregadas como caso limite na determinação e eliminação de modelos geométricos que Kepler considera irrealizáveis em um mundo sem orbes sólidos, as almas planetárias são noções muito próximas do magnetismo dos planetas, assim como a alma motriz do Sol não difere substancialmente da força solar. Para que possamos compreender melhor a noção kepleriana de alma planetária, voltemos agora nossa atenção para a explicação oferecida pelo astrônomo para a forma hexagonal dos flocos de neve.

\section{Da forma hexagonal dos flocos de neve e da alma da Terra como faculdade geometrizante}

O opúsculo Da neve hexagonal foi escrito em $1610^{6}$ e oferecido ao amigo de Kepler Johannes Matthäus Wackher von Wackhenfels ${ }^{7}$ como presente de ano novo em janeiro de 1611. O pequeno texto propõe uma investigação acerca da causa da forma hexagonal dos flocos de neve:

6 Ou em 1609, mas em todo caso após a publicação da Astronomia nova (Halleux. In: Kepler, 1975, p.3).

7 No dia 15 de março de 1610, Wackher von Wackenfels (1550-1619) foi à casa de Kepler para contarlhe das luas de Júpiter, recém descobertas por Galileu Galilei nas primeiras observações telescópicas da história da astronomia. Logo depois uma cópia do pequeno livro de Galileu, a Mensagem das estrelas (Sidereus nuncius) chegaria às mãos de Kepler, que respondeu prontamente com a publicação da Dissertação com o mensageiro das estrelas (Dissertatio cum nuncio sidereo), ainda em 1610 (Caspar, 1993, p.161-89). 
Visto que sempre é assim, que toda vez que começa a nevar aquelas primeiras partículas de neve manifestam a forma de um asterisco de seis ângulos, é necessário que haja uma causa determinada. Pois se acontece por acaso, por que não tombam igualmente com cinco ou sete ângulos, mas sempre com seis, contanto que não estejam ainda aglomeradas em grande número e confusas por um impulso diverso, mas esparsas e distintas? (Kepler, 1975, p.56; Kepler, 1938-, v.4, p.265)

Kepler parte da premissa de que, quando podem ser observados isoladamente, os flocos de neve apresentam a forma de uma estrela de seis pontas. Porque a observação da forma hexagonal não é casual mas ocorre sempre que são satisfeitas as condições que fecham a passagem acima, deve haver uma causa determinada para a associação da figura hexagonal aos flocos de neve. A investigação que leva à descoberta dessa causa constitui o objeto do pequeno texto, e é conduzida por Kepler através do exame de uma série de possibilidades, eliminadas uma a uma até que ele chegue a uma certa faculdade formadora (facultas formatrices) da alma da Terra.

Além dos flocos de neve, Kepler trata no texto com maior ou menor detalhe de um conjunto heterodoxo de fenômenos terrestres ${ }^{8}$ onde se manifestam figuras geométricas regulares: os cristais, as flores, as sementes de romã e as colméias das abelhas. Essas regularidades observadas na região terrestre, onde os corpos são continuamente gerados e destruídos, apontam para a dissolução da dicotomia entre céu e terra como mundos distintos, e reforçam a idéia de um mundo uno e geometricamente estruturado. Por esse motivo, o opúsculo Da neve hexagonal é do maior interesse do ponto de vista da posição kepleriana relativamente à existência de uma estrutura matemática do mundo e à possibilidade de aplicação das matemáticas ao estudo da natureza.

A esse interesse que remete ao que talvez pudéssemos chamar de uma teoria kepleriana do conhecimento, vem somar-se um outro, mais específico e relativo ao estatuto das almas planetárias na Astronomia nova. Se a causa eficiente da forma hexagonal dos flocos de neve deve ser atribuída a uma faculdade da alma da Terra, isso significa que estamos diante de um texto posterior à Astronomia nova, em que Kepler se pronuncia abertamente a favor das almas planetárias. É importante entender o que exatamente Kepler entende por essas almas, quais faculdades ele associa a elas, e em que medida elas podem legitimamente fazer parte da nova física dos céus. Procuramos mostrar que, longe de entrar em conflito com restante da astronomia física

8 Kepler percebe claramente que no heliocentrismo deixa de fazer sentido a distinção entre os mundos terrestre e celeste. Mantivemos a terminologia tradicional porque ela torna a discussão mais clara, mas o leitor deve atentar para o fato de que essa distinção é constantemente criticada por Kepler. 
kepleriana, a noção de alma planetária relaciona-se estreitamente com alguns dos pressupostos mais fundamentais dessa astronomia.

Como observou Rhonda Martens (2000, p.65), na Astronomia nova, mesmo as almas e mentes planetárias, se existirem, devem operar segundo as leis naturais ou não poderiam funcionar como causas eficientes. Além disso, o uso que Kepler faz dos arquétipos geométricos na sua astronomia reflete uma visão de mundo em que, sob as aparências caóticas e diversas jaz uma ordem simples, um padrão a ser descoberto. A astronomia é filha da álgebra e da geometria, mas enquanto a álgebra é para Kepler uma "arte de mercadores", uma técnica eminentemente instrumental, a geometria de Euclides determina a estrutura de um mundo que foi criado da maneira mais perfeita possível ao mesmo tempo em que garante que haja uma ligação estreita entre a razão humana e o mundo.

Na investigação sobre a causa da forma hexagonal dos flocos de neve, Kepler começa por descartar que, essa possa estar situada na matéria a partir da qual se formam esses flocos, o vapor. Vejamos rapidamente como se constrói o seu argumento. A explicação desdobra-se em duas: em primeiro lugar, a figura hexagonal simplesmente não é observada no vapor. A essa justificativa empírica vem somar-se uma outra: a figura hexagonal não poderia existir no vapor em virtude da própria definição de figura como o limite de algo, visto que o vapor resulta da "resolução do humor subterrâneo" (resolutione humoris subterranei) e escoa sem limitar-se por si mesmo. Se a causa não está na matéria, Kepler conclui, ela deve ser procurada no agente (Kepler, 1975, p.56; Kepler, 1938-, v.4, p.265). Mais adiante, no exame da forma geométrica, observada também nas colméias das abelhas, Kepler reitera a impossibilidade de associar a causa da figura de um corpo à sua matéria constituinte: "A matéria não está em causa. Com efeito, em parte alguma as abelhas encontram semelhantes pequenas bolsas rômbicas já preparadas, as quais elas uniriam e atariam para edificar suas casinhas" (Kepler, 1975, p.59; Kepler, 1938-, v.4, p.267).

A forma das colméias não pode ser explicada a partir da matéria que as constitui simplesmente, porque não se observa na natureza a existência desses elementos previamente estruturados, dos quais as abelhas poderiam se servir. Neste caso, Kepler explica: "A razão por que a própria natureza da abelha tem como propriedade o instinto de construir preferencialmente conforme esta figura é que tal arquétipo foi nela impresso pelo criador; e nem a cera, nem os pequenos corpos das abelhas, nem o crescimento têm aqui qualquer eficácia" (Kepler, 1975, p.63; Kepler, 1938-, v.4, p.269). Aos seres humanos foi transmitida a capacidade de conhecer a geometria e de compreender os arquétipos impressos na natureza, inclusive o arquétipo hexagonal que Deus imprimiu na natureza das abelhas. 
As leis da arquitetura das abelhas, Kepler prossegue, foram prescritas por Deus de acordo com a finalidade das colméias. Em primeiro lugar, o volume ou capacidade de armazenamento de uma colméia depende de sua forma geométrica. A forma circular é aquela que encerra a maior área, e a princípio poder-se-ia esperar que os elementos da colméia tivessem a forma de cilindros. No entanto, outras condições devem ser satisfeitas. Para que a colméia ofereça boa resistência e para que o frio não se insinue entre seus elementos, estes devem ser adjacentes. Além disso, se as paredes são compartilhadas o trabalho de cada abelha é diminuído. Ora, colocados lado a lado os círculos não preenchem um plano, e em um tal arranjo restariam espaços vazios. As únicas figuras geométricas capazes de preencher um plano são: o triângulo, o quadrado e o hexágono, e destas o hexágono é aquela que pode gerar um compartimento mais volumoso. Finalmente, os corpos das abelhas se alojam de maneira mais cômoda nos alvéolos hexagonais do que aconteceria caso eles tivessem a forma cúbica. Essas considerações envolvem aspectos materiais do funcionamento das colméias, e o fato de que é possível explicar a forma das colméias através de tais aspectos exclui a necessidade de atribuir uma faculdade contemplativa à alma das abelhas:

Estas razões que têm em vista a necessidade material são por conseguinte suficientes, assim eu penso, para que me dispense de filosofar aqui sobre a perfeição, a beleza ou a nobreza da figura rômbica; e nem é de se inquietar [em explicar] como a essência da alma que está na abelha é atraída pela contemplação da figura que ela fabrica; o que teria sido de se tentar caso nenhum uso da figura tivesse aparecido. (Kepler, 1975, p.64; Kepler, 1938-, v.4, p.270)

Agora, se também no caso da neve a causa da figura geométrica deve ser atribuída ao agente, o frio se apresenta, nos diz Kepler, como a primeira possibilidade. A reflexão mais cuidadosa, porém, revela que o frio "é mera privação, à qual não pertence nenhuma mente que fabrica hexágonos nem qualquer operação" (Kepler, 1975, p.66; Kepler, 1938-, v.4, p.271). A causa deve ser atribuída ao calor que se encontra no vapor, e que deve ser expulso por ocasião da formação dos flocos de neve. Que o agente da figura hexagonal não se encontra no exterior, mas no centro de cada estrela, é de resto sugerido. Kepler observa pela configuração dos flocos de neve: "Acrescente que todos os filamentos se estendem para fora na direção oposta do centro, seja da estrela, seja da dupla interseção, quase como as agulhas nos ramos do pinheiro; o que é indício de que a força formadora repousa no centro, e dali se espalha igualmente em todas as direções" (Kepler, 1975, p.71-2; Kepler, 1938-, v.4, p.274). Resta explicar como o calor produz a forma hexagonal e com qual finalidade. No texto, Kepler remete às figuras regulares das plantas: 
Assim pois, tendo examinado todas essas coisas que se apresentam, eu julgo que a causa da figura hexagonal na neve não é outra senão aquela das figuras regulares e dos números constantes nas plantas. Nada aqui ocorre sem que haja uma razão suprema, certamente não aquela que seria inventada pelo discurso racional, mas aquela que teria existido originalmente no projeto do criador e que, desde o princípio até o presente, estaria conservada na admirável natureza das faculdades dos animais. Da mesma maneira, eu também não acredito que na neve essa figura regular exista por acaso. (Kepler, 1975, p.73; Kepler, 1938-, v.4, p.275)

A finalidade e a origem da forma hexagonal são reveladas através do exame de duas objeções ao paralelo entre os flocos de neve e as formas regulares encontradas nas plantas. Em primeiro lugar, poder-se-ia objetar que, ao contrário do que ocorre com as plantas, a forma dos flocos de neve não é fixa e durável (certae et durabilis). Além disso, as plantas são providas de faculdades que determinam suas formas diversas, e o mesmo não se pode dizer dos flocos de neve, desprovidos de alma. O exame da primeira objeção revela que a forma hexagonal dos flocos de neve não visa à permanência de um corpo natural, resulta do embate entre o calor do vapor que o frio circundante. A forma hexagonal observada nos flocos é aquela como o calor se organiza antes de ceder ao frio (Kepler, 1975, p.74; Kepler, 1938-, v.4, p.275-6). Quanto à segunda objeção, ela é respondida pela observação de que as figuras das plantas não são singulares, mas rebentos (soboles) de uma mesma faculdade universal, situada na Terra (Kepler, 1975, p.74; Kepler, 1938-, v.4, p.276). "Existe portanto no corpo da Terra uma faculdade formadora cujo veículo é o vapor, assim como a respiração é [o veículo] da alma humana..." (Kepler, 1975, p.73; Kepler, 1938-, v.4, p.275). As almas são, escreve Kepler, providas do conhecimento das diversas figuras geométricas regulares:

Em primeiro lugar, todo o gênero das almas é aparentado às figuras geométricas e regulares, ou cosmopoéticas, o que pode ser provado através de muitos exemplos. Pois as almas são cópias várias do Deus criador. E é certamente na mente de Deus que se estabelece a verdade, co-eterna com Deus, dessas figuras. (Kepler, 1975, p.75-6; Kepler, 1938-, v.4, p.276)

Desse modo, aproximam-se as explicações das diversas figuras geométricas encontradas na região terrestre: as figuras das colméias das abelhas, das flores, dos flocos de neve, são todas produzidas por almas que têm em comum a afinidade com as formas regulares da geometria, a elas transmitidas pelo Criador. Elas funcionam como mediadores que têm o papel de transmitir continuamente aos corpos as formas geométricas que lhes são adequadas. No caso das plantas e das colméias, as almas das próprias plantas ou das abelhas funcionam como um mediador entre a influência da alma da Terra e a produção das figuras. No caso dos flocos de neve não há essas almas intermediárias, e a ação da alma da Terra se dá imediatamente atra- 
vés do vapor, seu veículo natural. A alma da Terra é portanto definida aqui como uma entidade eminentemente geometrizante, que imprime nos corpos naturais as figuras geométricas que neles observamos.

\section{Conclusão: das almas dos planetas na Astronomia nova}

Na Astronomia nova, as almas planetárias são equivalentes às forças magnéticas, e surgem no contexto da determinação precisa do modo de operação dessas forças. Ainda que o argumento do livro tenha o objetivo de estabelecer uma astronomia baseada unicamente em "causas naturais ou corpóreas", as almas planetárias da tradição são importantes hipóteses provisórias na determinação dos percursos percorridos pelos planetas. Por outro lado, e isto talvez seja mais importante, a força solar kepleriana é uma emanação imaterial (species immateriata), concebida segundo o exemplo do magnetismo, que não é "corpórea" senão porque geometricamente estruturada. Ora, no estudo sobre os flocos de neve, Kepler chega à conclusão de que a Terra possui uma faculdade geometrizante que também age sobre os cristais e as plantas, e no texto não lhe são atribuídas outras potências senão a de imprimir formas geométricas. Apesar dos diferentes contextos em que as almas dos planetas são introduzidas nesses dois casos, podemos observar que a geometria, é em ambos os casos, é a idéia central. Acreditamos assim, contra Bruce Stephenson, que o uso de almas planetárias na Astronomia nova não é meramente retórico, mas que estas, entendidas como potências que operam segundo leis geométricas, são parte importante da maneira como Kepler compreende a estrutura matemática da natureza. Não esperamos ter esgotado aqui as dificuldades que envolvem o tema, mas apenas ter apontado para o fato de que, a despeito do projeto de fundação de uma astronomia física que orienta o trabalho de Kepler, mentes e almas planetárias continuam a desempenhar um papel importante na sua concepção de natureza e na sua maneira de encarar o ofício do astrônomo.

ITOKAZU, Anastasia Guidi. Mathematical nature: of the Earth's soul as a geometrising power in Johannes Kepler's opuscule Of Hexagonal Snow. Trans/Form/ Ação, (São Paulo), v.31(1), 2008, p.73-86.

- ABSTRACT: In the celestial physics presented in his New Astronomy, Kepler explains the planetary motions through the action of the solar motive force or power. In regard of the approximation, performed in the book, between celestial physics and explanations grounded upon "corporeal forces", the numerous moments when Kepler resources to the notions of planetary souls and minds are somehow striking. In the present article we discuss these underestimated ex- 
tracts from the New Astronomy, where Kepler employs the notions of planetary minds and souls. Intending to enlighten the subject, we have dealt in the second section with the definition of Earth's soul drawn by Kepler in his work on the regular shape of snowflakes, written right after the publication of the New Astronomy. Kepler ascribes the hexagonal shape of snowflakes to a certain forming faculty of the Earth's soul, which would act as a geometrizing power with the aim of optimizing the heat's departure during the freezing process.

- KEYWORDS: Kepler, physical astronomy, snowflakes, soul, mind.

\section{Referências bibliográficas}

BONER, P. G. "Soul searching with Kepler: an analysis of anima in his astrology". In: Journal for the history of astronomy, 36, 2005, p.7-20.

CASPAR, M. Kepler. Nova Iorque: Dover, 1993.

EUCLIDES. Elements. Trad. Thomas L. Heath, 3 vols., Nova Iorque: Dover, 1956.

HEATH, T.L. A History of Greek Mathematics. v.1, Nova Iorque: Dover, 1981.

ITOKAZU, A. G. Astronomia nova: a história da guerra contra Marte como exposição do método astronômico de Kepler. Tese de doutorado. IFCH/UNICAMP, 2006a.

A força que move os planetas: da noção de species immateriata na astronomia de Johannes Kepler. Cadernos de História e Filosofia da Ciência, série 3, v.16, 2/2006b, p.211-31.

KEPLER, J. Mysterium cosmographicum. In: CASPAR, M \& W. VON DYCK (ed.) Gesammelte Werke. Munique: Bayerische Akademie der Wissenschaften, 1938, v.1.

Astronomia nova. In: CASPAR, M \& W. VON DYCK (ed.) Gesammelte Werke. Munique: Bayerische Akademie der Wissenschaften, 1938, v.3.

De nive sixangula. In: CASPAR, M \& W. VON DYCK (ed.) Gesammelte Werke. Munique: Bayerische Akademie der Wissenschaften, 1938, v.4, p.26380.

Kepler an Herwart von Hohenburg in München, [carta 325, 10 de fevereiro de 1605]. In: CASPAR, M \& W. VON DYCK (ed.) Gesammelte Werke. Munique: Bayerische Akademie der Wissenschaften, 1938, v.15, p.145-7.

El secreto del universo. Trad. Eloy Rada García. Madri: Alianza editorial, 1992a.

New astronomy. Trad. William H. Donnahue. Cambridge: Cambridge University Press, 1992.

L' etrenne ou la neige sexangulaire. Trad. Robert Halleux. Paris: Vrin, 1975.

MARTENS, R. Kepler's philosophy and the New Astronomy. Princeton: University Press, 2000.

STEPHENSON, B. The music of the heavens. Princeton: University Press, 1994.

Kepler's physical astronomy. Nova Iorque: Springer-Verlag, 1987.

TOSSATO, C. R. Força e harmonia na astronomia física de Johannes Kepler. Tese de doutorado. São Paulo: FFLCH/USP, 2003. 